\title{
PERCEIVED FACTORS INFLUENCING THE CHOICE OF ANTENATAL CARE AND DELIVERY CENTRES AMONG CHILDBEARING WOMEN IN IBADAN NORTH SOUTH-WESTERN, NIGERIA
}

EWA, E. E., ${ }^{*}$ LASISI, C. J., ${ }^{2}$ MADUKA, S. O., ${ }^{1}$ ITA, A. E., ${ }^{3}$ IBOR, U. W. ${ }^{2}$ and ANJORIN, 0. A. ${ }^{2}$ http://dx.doi.org/10.4314/ejesm.v5i4.6

Received 13th June 2012; accepted 1st August 2012

\begin{abstract}
The aim of the study was to investigate the supposed factors apart from socioeconomic influencing the choice of antenatal care and delivery centres among childbearing women in Ibadan North Local Government Area of Oyo State. Data were obtained through the administration of two hundred and thirty-one (231) copies of structured questionnaire to childbearing women in four antenatal centres normally utilized in the area. Data obtained were analyzed using descriptive and inferential statistical tools. The Chi Square result indicated that awareness of ANC significantly influenced place of delivery ( $p<0.05)$, while the result of Pearson's correlation indicated a low negative and insignificant association between distance and utilization of ANC and delivery services ( $r$-Value $=-0.04, p>0.05)$. The study revealed that husband's decision or preference of ANC and privacy constituted the prominent factors that influenced the choice of ANC as well as place of delivery. It further revealed that the highest patronage of ANC and delivery centres was achieved with distance of $<5 \mathrm{~km}$, while the lowest patronage was achieved when the approximate distance was $>10 \mathrm{~km}$. Based on the findings of the study, it was recommended that husbands should be encouraged and educated on the need to give their wives free hand in deciding places of ANC and delivery centres.
\end{abstract}

Keywords: Antenatal Care, Utilization, Socioeconomic Characteristics, Childbearing Women

\section{Introduction}

In the developed countries, the availability and accessibility of pregnant women to high quality health care has made maternal deaths a rare event, while in the developing countries, the risk of maternal death for a pregnant woman is 1 in every 48 deliveries as a result of availability of low quality health care (Iyaniwura and Yussuf, 2009). Adequate antenatal care (ANC) and skilled obstetric assistance during delivery are important strategies that significantly reduce maternal mortality and morbidity (WHO, 2005). ANC provides avenue to provide pregnant women with information, treat existing social and medical conditions and screen for risk factors. However it is not enough to receive ANC, since majority of the fatal complications occur during or shortly after delivery (Fact Sheet, 2002). It is therefore important that pregnant women have skilled obstetric attendance during delivery. When a woman dies in childbirth, her infant and any other children's survival is threatened. Infants without mother are more likely to die within two years. Children up to 10 years whose mothers die are 3 to 10 times more likely to die within two years than children living with mothers. Every year an additional 2 million children worldwide are maternal orphans (WHO, 2005).

Indeed, lack of education and poor knowledge of maternal health care has contributes to delays in seeking care during pregnancy and child birth. Poverty is one of the major health determinants. Poor mothers are at high risk of developing pregnancy related complications, because they are not financially able to pay for the required services (UNFPA, 2006; Ibor et al., 2011). Maternal death has long term effects on a child's education and health. When a mother dies, older children often leave school to support their family. Children without a mother are less likely to be immunized, and are more likely to suffer from malnutrition (Anjorin, 2011). Almost all maternal deaths that occur in low and middle-income countries

\footnotetext{
${ }^{1}$ Department of Geography \& Environmental Science, University of Calabar, Nigeria.

${ }^{2}$ Department of Geography, University of Ibadan, Nigeria.

${ }^{3}$ Dept. of Environmental Health, College of Health Technology, Cross River State, Nigeria.

*Corresponding author: chidilasisi@ vahoo.com
} 
are mainly among the poorest of the poor (Adedotun, 2010). In addition, lacks of access to emergency obstetric care and delay for emergency referral have contributed to high maternal mortality in the area. Obstetrics complications are able to be treated in health institutions that are sufficiently equipped with supplies, (WHO, 2009) medications and fully staffed with capably trained health professionals, but in the area of study such facilities are not available thereby subjecting pregnant women to their faith, which in most cases result in deaths.

Studies show that the choice or utilization and accessibility of childbearing women to ANC and delivering services depend on several factors such as socioeconomic factors, geographic barriers and quality of services among others. For example Bakeera et al., (2009) studied community perceptions and factors influencing utilization of health services in Uganda. Results reveal that barriers to healthcare utilization exist for all the wealth categories along three different axes including: the health seeking process; health services delivery; and the ownership of livelihood assets. Income source, transport ownership, and health literacy were reported as centrally useful in overcoming some barriers to healthcare utilization for the 'least poor' and 'poor' wealth categories. Hadi (2003) carried out a study to determine approach to reaching the poor and disadvantaged to promote health equity in rural Bangladesh. He posits that although the health care system has significantly expanded in the rural areas of Bangladesh during the last two decades, the overall health status of the population has remained very poor because of the uneven distribution of health and other basic services. The study revealed that significant socioeconomic differentials in the access to and the utilization of health care in the study communities. Education and landownership were strong predictors of the health service use. Gender differential in health care was not significant. The access to and use of health care were much higher among the micro-credit program participants than non-participants.

Wagstaff (2002) asserted that improving the health of the poor and reducing health inequalities have become the central goals of many development programs. That equal access, however, depends upon the availability of services, organizations and financial capacity. Iyaniwura and Yussuf (2009) studied the utilization of antenatal care and delivery services in Sagamu, South Western Nigeria. Result among others shows that education and income of childbearing women positively affected the pattern of use of these services. Perceived quality of service was the most important factor which influenced the choice of facility for obstetric care. Moore et al., (2011) examined the utilization of health care services by pregnant mothers during delivery. They posit that poor utilization of health facilities during delivery by pregnant mothers is still a major cause of maternal and childhood morbidity and mortality in Nigeria. Factors responsible for non utilization of health facility for delivery include: Long distance to health facility, onset of labour at night. unavailability of means of transportation, lack of money for transportation, unsatisfactory services at health facility, unfriendly attitude of staff of the health facility, unavailability of staff at health facility, lack of urgency at health facility and previous uneventful delivery at the health facility. Buor (2002) noted that the key factors that affect utilization of maternal facilities are education, distance and service cost.

Furthermore, Okafor (1982) observed in the study of spatial location and utilization of health facilities in the Bendel State that utilization of these health facilities in the Bendel State that utilization of these health facilities is closely bound to their location since distant location implies a higher delivery price of health services. Stock (1983) in a study of distance and the utilization of health facilities in rural Nigeria found that the effect of distance decay in utilization levels varied according to the type of facility, social demographic variables and illness. Although, the per capita consumption of health care decreases exponentially for concentric distance band, villages showed great disparities in utilization rates which are only partly attribute to distance. The studies above identify different factors that affect the 
choice/utilization of ANC and delivery centres principally as a result of socioeconomic differentiates. This study therefore intends to evaluate the perceived factors influencing the choice of antenatal care and delivery centres among childbearing women in Ibadan North Local Government Area, Oyo State, Nigeria.

\section{Materials and Method Study Area}

Ibadan North Local Government Area is located approximately on longitude $8^{\circ} 5^{\prime}$ East of the Greenwich meridian and latitude $7^{\circ} 23^{\prime}$ North of equators (Fig 1). Ibadan North Local Government Area comprises 12 wards. The local government consists of multi-ethnic nationalities predominantly dominated by the Yoruba, Igbo, Edos, Urhobos, Itsekiris, Ijaws, Hausas, Fulani and foreigners who are from Europe, Asia and Other parts of the world. The inhabitants are mostly traders, university and polytechnic lecturers, civil servants, students etc. The Local Government also houses several educational institutions such as University of Ibadan University College Hospital (College of Medicine), The Polytechnic Ibadan and several private and public secondary and primary schools. This infrastructure makes Ibadan North Local Government Area to be ahead of other Local Government Areas.

The Local Government Area also houses several health care centers such as University College Hospital, Jaja health care centers, Adeoyo Hospital and several Maternity Centres and dispensaries. The

establishment of all these health-care facilities in the Local Government Area is due to the sensitivity of government to the healthy care of people resident within the boundaries of the local Government Area. Nevertheless, to safeguard the lives of pregnant women in the area, there has been the establishment of antenatal and health care delivery centers. Among which includes Adeoyo General Hospital, Oni and sons, Group medical, Ajaigbe Traditional Healing Centre, Oyarebu Ozege Memorial Traditional Hospital, Oluwa- keyin spiritual Healing Home and other primary health care and specialist hospital in and around the Local Government area.

\section{Sampling Procedure and Data Collection}

This study employed the multi-stage sampling technique involving three steps. In the first step, ante-natal centres normally utilized by childbearing women were selected, which included government hospital, private hospital, mission homes and traditional/herbal centres. In the second stage, two ANC centres were randomly selected from the government hospital, private hospital, mission homes and traditional centres. Thereafter, two hundred and forty childbearing women were purposively sampled across the eight selected ANC centres (i.e. 30 childbearing women were selected from each of the 8 centres). The fourth step of the survey involved the administration of questionnaire using accidental sampling techniques. This technique was chosen due to the problem of gathering or having the entire population of women at the same time. Responses obtained from the questionnaire mostly on socioeconomic and cultural characteristics of childbearing women as well as on utilization were transformed to dummy variables for statistical analyses (multiple regression analysis). The researchers personally visited the four ANCs and the research instrument (questionnaire) was self administered by hand to every childbearing woman. However, at the end of the survey, two hundred and thirty-one copies of questionnaire were used for analysis; nine were voided due to multiple responses and non-response.

\section{Data Analysis}

Data obtained from the questionnaire were analysed using tables, simple percentages and multiple regression analysis. In order to effectively carryout these tests, items in the questionnaire were coded for descriptive analysis and thereafter transformed or recoded into dummy variables. After these transformations, inferential analyses were applied. Analysis was carried out with the aid of SPSS (17.0) software for windows. 


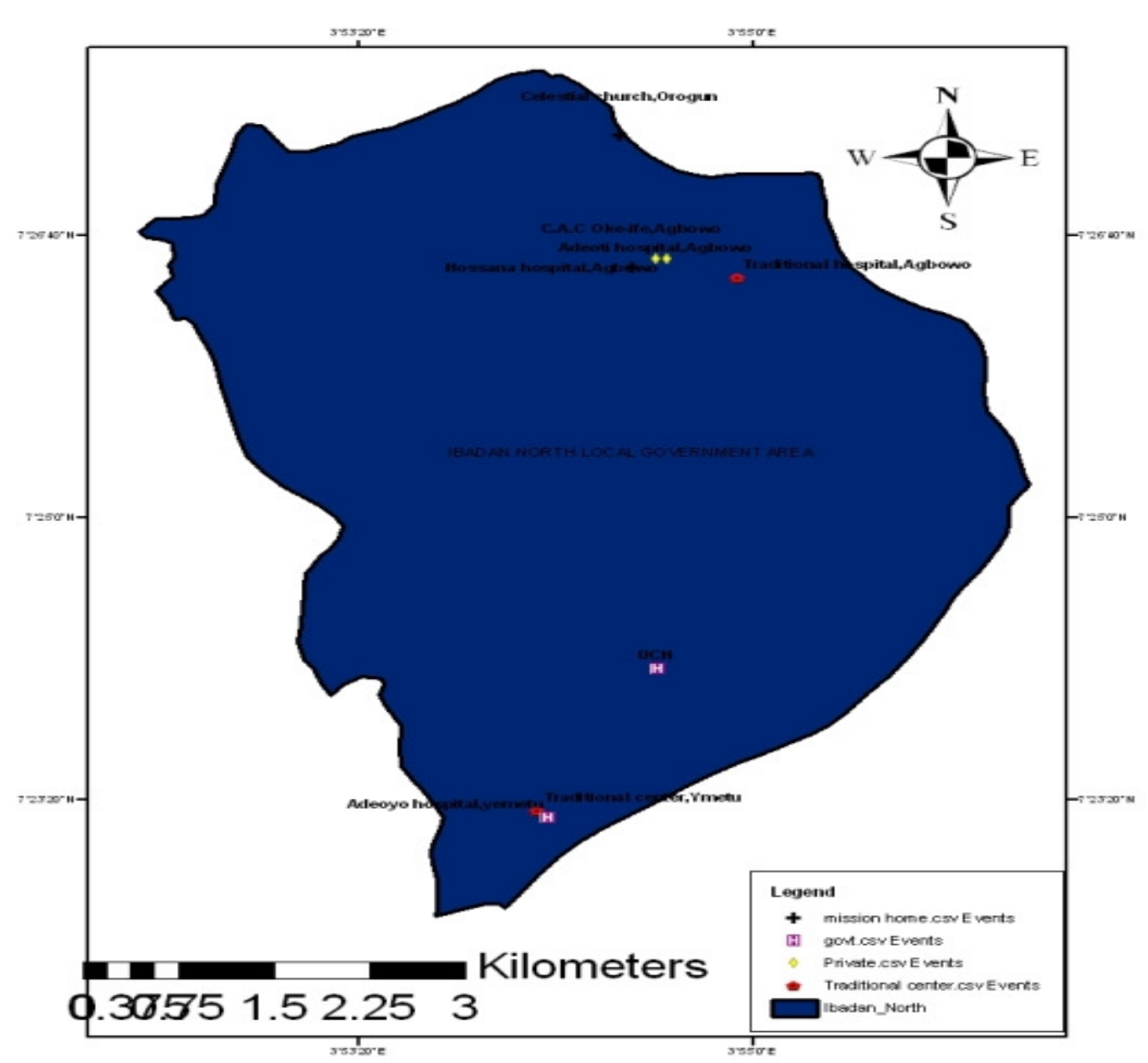

Figure 1 Ibadan north showing location of antenatal and delivery centers

\section{Results \\ Socio-cultural and Economic Characteristics of Childbearing Women}

Information on the socio-cultural and economic characteristics of childbearing women shows that the age range of the women was $18-45$ years, majority of them were within 31 - 45 years of age $(74.5 \%)$, while $25.5 \%$ representing 59 childbearing women were within the ages of $15-30$ years. Two hundred and twenty $(95.2 \%)$ were married, while $4.8 \%$ were single. Majority (61.5\%) of the childbearing women was Christians, $38.5 \%$ were Muslims and none practiced the traditional religion. Information on the education of childbearing women depicts that forty-one (17.7\%) had no formal education, $21.6 \%$ had primary school education, $29.9 \%$ had post-primary education, $28.1 \%$ had postsecondary education, while 2.6 had additional qualifications. The occupational information of childbearing women shows that majority, one hundred and fifteen $(49.8 \%)$ were traders, while $50.2 \%$ were farmers, civil servants, cleaners, teachers among others. The education and occupation of husbands depicts that $79.7 \%$ were educated, while $20.3 \%$ had no formal education; in addition, occupation of husbands reveals that $40.7 \%$ were traders, $18.6 \%$ were civil servants and $29.9 \%$ were drivers, technicians, engineers among others. Information on cultural preference of ANC shows that ANC is generally acceptable, while income shows that one hundred and eighteen $(51.1 \%)$ earn less that N10, 000 monthly. The information in the table implies that majority 
of the childbearing women as well as their husbands are literates as such have one form of awareness or the other on the relevance of centres during pregnancy. It also depicts that ANC is acceptable across different cultures as a way to safeguard the lives of women and their babies during pregnancy.

\section{Level of ANC and Delivery Services Awareness and Utilization}

Table 1 shows the level of ANC and delivery service awareness and utilization. The level of awareness of ANC and delivery services was ascertained by asking childbearing women if they had used any ANC and delivery service in their last or present pregnancy. The table interestingly reveals that two hundred and twenty (97\%) of childbearing women were aware of ANC and delivery centres, and had utilized it in their present or last pregnancy, while only $3 \%$ were not aware. This level of awareness is however unconnected with childbearing women's level of education as well as that of their husbands.

\section{Level of Awareness and Choice of ANC and Delivery Centres}

Table 2 shows the level of awareness and choice of ANC and delivery centres. It shows that out of two hundred and twenty-four (97\%) of childbearing women who were aware of ANC and delivery centres, eighty-five (37.9\%) made use of government hospitals during their last or present pregnancies; eighty-two $(36.6 \%)$ patronized private hospitals, while forty-two (18.8\%) and fifteen (6.7\%) utilized mission hospitals and traditional/herbal homes respectively. On the other hand, out of the seven (3\%) who were unaware of any ANC and delivery centres, three $(42.9 \%)$ were unaware of government hospitals and did not utilize them in their last pregnancies, one $(14.3 \%)$ did not patronize private hospitals, and traditional/herbal homes respectively, while two $(28.6 \%)$ were unaware of mission homes and as such did not make use of them in their last pregnancies. The high patronage or utilization of government and private hospitals by childbearing women may be attributed to their level of awareness (education) of their sophistication in handling pregnancy complications. Though majority of the women received ANC and sought assistance during delivery, some women were more likely to receive maternity care or use non-health institutions. This result implies that formal education has a positive effect on the use of ANC services, as educated women are more likely to have ANC during pregnancy, have more frequent visits and make use health facilities for delivery.

\section{Choice of ANC and Delivery Centres and Possible Reasons for the Choice}

Table 3 summarizes the reasons for childbearing women's choice of ANC \& place of delivery. The highest consideration for their choice of ANC \& place of delivery was to satisfy their husbands (32.9\%), 25.5\% used the chosen centres due to privacy attached to such places, while $23.4 \%$ chose the centres because of proximity to their house and place of work (office). However, out of the eighty-eight $(38.1 \%)$ childbearing women that chose government hospital, $33(37.5 \%)$ used it to satisfy their husbands, 25 (28.4\%) utilized it as a result of its proximity to their homes, offices or husband's office, the least reasons for utilizisng government hospital during pregnancy were cheapness $(5.7 \%)$ and sociocultural factors $(4.5 \%)$. For those that utilize private hospitals and mission homes, satisfaction of husbands' decision or preference and privacy were the main reasons for it utilization, while for traditional homes, nearness and privacy were the sole reasons for their patronage. The various reasons identified significantly influence childbearing women's choice of ANC and place of delivery $\left(\mathrm{X}^{2}=\right.$ $40.733, \mathrm{p}<0.05)$. In all, the information in the table reveals that husbands decision or preference of ANC and privacy constitute the prominent factors that influence the choice of ANC as well as place of delivery. Thus decision to seek maternal health care was associated with husband's willingness; as the key person in the decision-making process. 
Table 1 Level of awareness and utilization of ANC \& delivery services

\begin{tabular}{lcc}
\hline Options & Frequency & Percent \\
\hline Yes & 224 & 97.0 \\
No & 7 & 3.0 \\
Total & 231 & 100.0 \\
\hline
\end{tabular}

Table 2 Level of awareness and delivery centers normally utilized

\begin{tabular}{lccc}
\hline Delivery centers normally utilized & \multicolumn{2}{c}{ Level of awareness } & \\
\cline { 2 - 3 } & Awareness & Non awareness & Total \\
\hline Government hospitals & 85 & 3 & 88 \\
& $96.6 \%$ & $3.4 \%$ & $100.0 \%$ \\
Private hospitals & 82 & 1 & 83 \\
& $98.8 \%$ & $1.2 \%$ & $100.0 \%$ \\
Mission hospitals & 42 & 2 & 44 \\
Traditional/herbal homes & $95.5 \%$ & $4.5 \%$ & $100.0 \%$ \\
& 15 & 1 & 16 \\
\multicolumn{1}{c}{ Total } & $93.8 \%$ & $6.3 \%$ & $100.0 \%$ \\
$\%$ & 224 & 7 & 231 \\
& $97.0 \%$ & $3.0 \%$ & $100.0 \%$ \\
\hline
\end{tabular}

Table 3 Reason the choice of delivery centers usually utilized

\begin{tabular}{|c|c|c|c|c|c|c|}
\hline \multirow[b]{2}{*}{$\begin{array}{l}\text { Delivery centers } \\
\text { usually utilized }\end{array}$} & \multicolumn{5}{|c|}{ Reason for chosen ANC \& delivery centres } & \multirow[b]{2}{*}{ Total } \\
\hline & Privacy & Cheap & Nearness & $\begin{array}{l}\text { To satisfy } \\
\text { husband }\end{array}$ & $\begin{array}{l}\text { Socio- } \\
\text { cultural } \\
\text { factors }\end{array}$ & \\
\hline \multirow{2}{*}{$\begin{array}{l}\text { Government } \\
\text { hospitals }\end{array}$} & 21 & 5 & 25 & 33 & 4 & 88 \\
\hline & $23.9 \%$ & $5.7 \%$ & $28.4 \%$ & $37.5 \%$ & $4.5 \%$ & $100.0 \%$ \\
\hline \multirow[t]{2}{*}{ Private hospitals } & 23 & 20 & 14 & 25 & 1 & 83 \\
\hline & $27.7 \%$ & $24.1 \%$ & $16.9 \%$ & $30.1 \%$ & $1.2 \%$ & $100.0 \%$ \\
\hline \multirow[t]{2}{*}{ Mission hospitals } & 11 & 4 & 6 & 16 & 7 & 44 \\
\hline & $25.0 \%$ & $9.1 \%$ & $13.6 \%$ & $36.4 \%$ & $15.9 \%$ & $100.0 \%$ \\
\hline \multirow{2}{*}{$\begin{array}{l}\text { Traditional/herbal } \\
\text { homes }\end{array}$} & 4 & 0 & 9 & 2 & 1 & 16 \\
\hline & $25.0 \%$ & $.0 \%$ & $56.3 \%$ & $12.5 \%$ & $6.3 \%$ & $100.0 \%$ \\
\hline \multirow{2}{*}{$\begin{array}{c}\text { Total } \\
\%\end{array}$} & 59 & 29 & 54 & 76 & 13 & 231 \\
\hline & $25.5 \%$ & $12.6 \%$ & $23.4 \%$ & $32.9 \%$ & $5.6 \%$ & $100.0 \%$ \\
\hline
\end{tabular}




\section{Analysis of the Effect of Awareness on Place on Delivery}

The first hypothesis which states that awareness of ANC significant influences place of delivery was tested using Chi Square statistical analysis. The result of Chi Square is shown in table 4. The table shows that calculated Chi value of 8.425 is greater than the tabulated or p-value of 0.038 at $5 \%$ significance level. Based on this result, the hypothesis that awareness of ANC significant influence place of delivery is accepted; it therefore implies that awareness of ANC significant influences place of delivery.

\section{Reason for Non- utilization of ANC and Delivery Centres}

Figure 1 gives information on possible reasons that can hinder non-utilization of ANC and delivery centres by childbearing women during pregnancy. According to the information, eighty-nine (38.5\%) believed non-affordability in terms of insufficient money to pay for the services can prevent pregnant women from attending ANC, sixtyfour $(27.7 \%)$ attributed the non-utilization of ANC and delivery centres to distance from their homes, as such they patronize noninstitutional centres nearest to them. In addition, sixty $(26 \%)$ posited that the preference of traditional homes to institutional centres influence pregnant women from attending ANC. This perhaps is completely cultural, as most mothers irrespective of their level of education still utilize traditional homes, which to some is safer, has less complication and cheaper. According to Iyaniwura and Yussuf (2009) increased proportion of deliveries at TBA (traditional birth attendants) home may also be associated with the prevalent supernatural concept of diseases and safety in many African communities.

Approximate Distance from Home or Office to Nearest ANC and Delivery Centres

Figure 2 gives information on the approximate distance taken by childbearing women to access the nearest ANC and delivery services. The fig shows that seventy
(30.3\%) and sixty (26\%) of the childbearing women spent $2-4 \mathrm{~km}$ to access ANC, while thirty-eight (16.4\%) spent $0.5-1 \mathrm{~km}$ to utilize nearest ANC and delivery service. However, the level of ANC patronage as shown in the figure decreased with increasing distance, for example, the highest patronage of ANC and delivery services or centres was achieved with distance of $<5 \mathrm{~km}$, while the lowest patronage was achieved when the approximate distance to ANC was more than $10 \mathrm{~km}$. This indeed implies that distance is a function of access, as both attributes share indirect relationship. That is, as distance to nearest ANC and delivery centre increases, the utilization level of available ANC centres decreases.

\section{Distance and the Utilization of ANC}

Table 5 gives information on ANC and delivery centres utilized by childbearing women in relation to distance. The table shows that out of the 7 childbearing women who covered $0.5 \mathrm{~km}$ to access ANC and delivery centres, $6(85.7 \%)$ used government hospitals, while only one childbearing woman used mission hospitals; for distance of 0.5 $1 \mathrm{~km}, 16(51.6 \%)$ used government hospitals, $11(35.5 \%)$ used private hospitals, while the lowest utilized ANC was traditional homes, this is not surprising, as traditional homes are normally found at the outskirts of the city; also, for distance of $2-3 \mathrm{~km}, 41.7 \%$ and $38.3 \%$ of the childbearing women utilized government and private hospital due probably to their wide spread and perceived quality, while the least patronized centre the traditional home. In addition, for distance of $>5 \mathrm{~km}$, private and mission hospitals were most utilized, while private hospital happened to be used with increasing distance $\mathrm{f}>10 \mathrm{~km}$. The observation here is that, though distance is a barrier to the full utilization of ANC and delivery services, increased in income accompanied by perceived quality service of a centre determines the utilization of a particular facility by childbearing women. However, distance from the result of the chi square does not significantly determine choice of a particular $\mathrm{ANC}$ and delivery centre $\left(\mathrm{X}^{2}=\right.$ 31.737; $\mathrm{p}>0.05$ ). 
Analysis of the Effect of Distance on the Utilization of ANC and Delivery Services

The second hypothesis that utilization of ANC is inversely related to distance was tested using Pearson's correlation analysis. The result of Pearson's correlation is presented in table 6 . From the table, the $r$ value indicates there is a low negative association between distance and utilization of ANC and delivery services (-0.04) which is insignificant $(p>0.05)$ at $5 \%$ level of significance. With this, the null hypothesis that utilization of ANC is not inversely related to distance is accepted, while the alternate hypothesis is rejected. The result further implies that distance and utilization are inversely interrelated in that an increase in one variable (say distance) would bring about a follow-on decrease in the other (ANC utilization) and vice versa. What this implies is that though distance from the result does not have significant relationship with utilization of ANC, but it shows a negative relationship actually exists even if the magnitude of impact is insignificant.

\section{Discussion}

The study reveals that awareness of ANC substantially influences childbearing women choice on place of delivery. This again is apparent, as educated mothers would be more aware of the importance of ANC and delivery services, and as such utilize them during pregnancy. Indeed, increased awareness of the relevance of ANC, as is known would accelerate the search for ANC during pregnancy. The importance of awareness in influencing the use of ANC and place of delivery has also been reported by earlier studies, for example, Jimoh (2003) observed a high level of awareness of the need for special care for women during pregnancy and majority of the women knew where they could receive ANC in their community. $\mathrm{He}$ thereafter attributed the high proportion of women who utilize maternal health care to increased formal education as well as easy access to the mass media.

The study reveals that though distance in the present study is insignificant in influencing the choice of ANC, it nevertheless shows that a negative relationship actually exists. This is evident as mothers with higher income tend to utilize facilities far away from their place of residence, and the possible reason is perceived quality of service as well as husband's preference of a particular facility. Indeed, husband's encouragement to seek maternal health care seems to exert considerable impact on selection of ANC and delivery centres. This is because, majority of childbearing women in this study are encouraged by their husbands to seek care during pregnancy and childbirth. Women encouraged by their husbands are however more likely to use ANC and delivery centres irrespective of the distance. This result corroborates earlier findings like those of Mrisho et al., (2007), Pembe et al., (2008) that husband seems to be the most key person in the decision-making process in the utilization of ANC and delivery centres. They also posit that this decision is not related to the women's economic status since they are dependent on men.

\section{Conclusion}

The study reveals that childbearing women are aware of the need for antenatal care and assistance during labour. Majority of them use orthodox health facilities for ANC and delivery services, while a negligible proportion still uses unorthodox institutions. The perceived factors that influence the choice of ANC and delivery centres are husband's decision or preference, inherent privacy, nonaffordability and distance. The study shows that though distance is a barrier to the full utilization of ANC and delivery services, but affordability accompanied by perceived quality service of a centre determines the utilization of a particular facility. The theoretical and practical implication of result obtained is that demand for antenatal care and delivery services generally declines with increasing instance. Despite this, it clearly means that ANC and delivery services are services patients are willing to travel long distances to attain based principally on affordability and perceived quality service. The study therefore recommends that husbands should give their wives free hand in deciding places of ANC and delivery centres. 


\section{References}

Adedotun, E. (2010), Maternal Mortality: Dying to Give Hope? http://www.learning partnership.org/blog/2010/02/nigeriamaternal-mortality/ Anjorin, O. A. (2011), Utilization of Antenatal and Delivery Services among Child-Bearing Women in Ibadan North L. G. A., Oyo State, Nigeria. Unpublished M.Sc. Thesis, University of Ibadan, Nigeria

Bakeera, S. K., Wamala, S. P., Galea, S., State, A., Peterson, S. and Pariyo, G. W. (2009), Community Perceptions and Factors Influencing Utilization of Health Services in Uganda. International Journal for Equity in Health, 8:25

Fact Sheet (2002), The Safe Motherhood Initiative. Family Care International (FCI), Safe Motherhood Inter Agency Group (IAG). www.safemotherhood. figures/initiative.htm

Hadi, A. (2003), An approach to reaching the Poor and Disadvantaged to Promote Health Equity in rural Bangladesh. Research and Evaluation Division BRAC 75 Mohakhali, Dhaka, Bangladesh.

Ibor, U. W., Anjorin, O. A., Ita, A. E., Out, M. A. and Bassey, T. I. (2011), Utilization of Antenatal Care in Ibadan North Local Government Area, Oyo State, Nigeria. Trends in Medical Research, 6: $273-280$

Iyaniwura, C. A. and Yussuf, Q. (2009), Utilization of Antenatal care and Delivery services in Sagamu, South Western Nigeria. African Journal of Reproductive Health, 13(3): $110-122$

Jimoh, A. A. G. (2003), The Scourge of AIDS in the New Millennium: Socio-economic
Implications in an Emerging Economy. Which Way Out? Human Resource Journal, 11: 1419

Moore, B. M., Alex-Hart, B. A. and George, I. O. (2011), Utilization of Health Care Services by Pregnant Mothers during Delivery: A Community based Study in Nigeria. Journal of Medicine and Medical Science, 2(5): 864-867. Mrisho, M., Schellenberg, J. A., Mushi, A. K., Obrist, B., Mshinda, H., Tanner, M. and Schellenberg, D. (2007), Factors Affecting Home Delivery in Rural Tanzania. Tropical Medicine \& International Health, 12 (7): 862 $-872$

Okafor, S. I. (1982), Spatial Location and Utilization of Health Facilities. Studies in Third World Societies, 19: 79 - 98

Pembe, A. B., Urassa, D. P., Carlstedt, A., Lindmark, G., Nystrom, L. and Darj, E. (2008), Rural Tanzania Women's Awareness of Danger Signs of Obstetric Complications. BMC Pregnancy and Childbirth, 9

Stock, R. (1983) Distance and the Utilization of Health Facilities in Rural Nigeria. Soc Sci Med, 17 (9): 563 - 570

UNFPA (2006), Maternal Mortality Update Report.

www.unfpa.org/webdav/site/global/shared.

Wagstaff, A. (2002) Poverty and Health Sector Inequalities. Bulletin of the WHO, 80(2): 97-105.

WHO (2009), Country Cooperation Strategy at a Glance. http://www.who.int/countryfocus World Health Organization (WHO) (2005) Factsheets Maternal Mortality. http://www.who.int/making_pregnancy_safer/ events/2008/mdg5/factsheet_maternal_mortali ty.pdf.

Table 4 Chi-Square Tests

\begin{tabular}{lccc}
\hline Test statistics & Value & df & Asymp. Sig. (2-sided) \\
\hline Pearson Chi-Square & 8.425 & 3 & 0.038 \\
Likelihood Ratio & 6.192 & 3 & 0.103 \\
Linear-by-Linear Association & 4.680 & 1 & 0.031 \\
N of Valid Cases & 231 & & \\
\hline
\end{tabular}




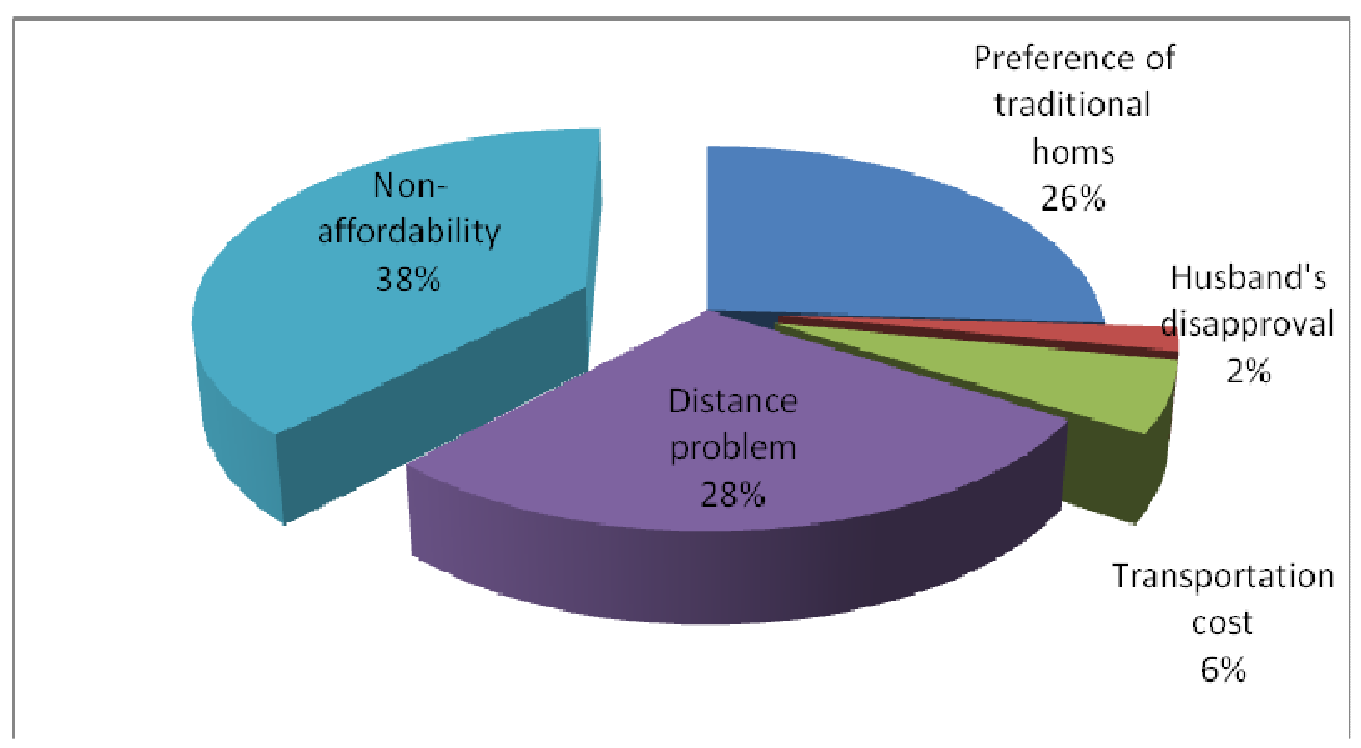

Figure 1 Percieved Reason for non-utilization of ANC and Delivery Centres

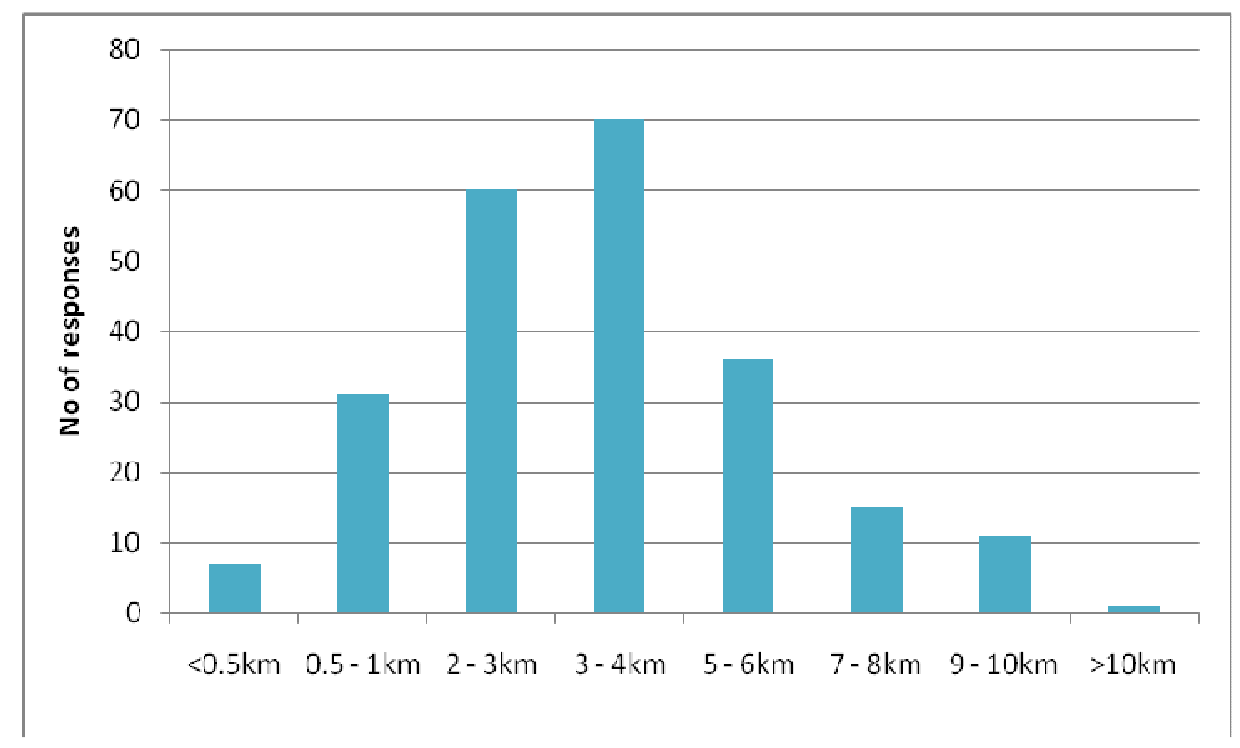

Figure 2 Approximate distance to the bearest ANC and Delivery Centers 
Table 5 ANC and delivery centres utilized and approximate distance

\begin{tabular}{|c|c|c|c|c|c|}
\hline \multirow[b]{2}{*}{ Approximate distance } & \multicolumn{4}{|c|}{ ANC \& delivery centers utilized } & \multirow[b]{2}{*}{ Total } \\
\hline & $\begin{array}{l}\text { Government } \\
\text { hospitals }\end{array}$ & $\begin{array}{c}\text { Private } \\
\text { hospitals }\end{array}$ & $\begin{array}{l}\text { Mission } \\
\text { hospitals }\end{array}$ & $\begin{array}{l}\text { Traditional/herbal } \\
\text { homes }\end{array}$ & \\
\hline \multirow[t]{2}{*}{$<0.5 \mathrm{~km}$} & 6 & 0 & 1 & 0 & 7 \\
\hline & $85.7 \%$ & $.0 \%$ & $14.3 \%$ & $.0 \%$ & $100.0 \%$ \\
\hline \multirow[t]{2}{*}{$0.5-1 \mathrm{~km}$} & 16 & 11 & 3 & 1 & 31 \\
\hline & $51.6 \%$ & $35.5 \%$ & $9.7 \%$ & $3.2 \%$ & $100.0 \%$ \\
\hline \multirow[t]{2}{*}{$2-3 \mathrm{~km}$} & 25 & 23 & 9 & 3 & 60 \\
\hline & $41.7 \%$ & $38.3 \%$ & $15.0 \%$ & $5.0 \%$ & $100.0 \%$ \\
\hline \multirow[t]{2}{*}{$3-4 \mathrm{~km}$} & 29 & 24 & 11 & 6 & 70 \\
\hline & $41.4 \%$ & $34.3 \%$ & $15.7 \%$ & $8.6 \%$ & $100.0 \%$ \\
\hline \multirow[t]{2}{*}{$5-6 \mathrm{~km}$} & 7 & 14 & 10 & 5 & 36 \\
\hline & $19.4 \%$ & $38.9 \%$ & $27.8 \%$ & $13.9 \%$ & $100.0 \%$ \\
\hline \multirow[t]{2}{*}{$7-8 \mathrm{~km}$} & 2 & 7 & 6 & 0 & 15 \\
\hline & $13.3 \%$ & $46.7 \%$ & $40.0 \%$ & $.0 \%$ & $100.0 \%$ \\
\hline \multirow[t]{2}{*}{$9-10 \mathrm{~km}$} & 3 & 3 & 4 & 1 & 11 \\
\hline & $27.3 \%$ & $27.3 \%$ & $36.4 \%$ & $9.1 \%$ & $100.0 \%$ \\
\hline \multirow[t]{2}{*}{$>10 \mathrm{~km}$} & 0 & 1 & 0 & 0 & 1 \\
\hline & $.0 \%$ & $100.0 \%$ & $.0 \%$ & $.0 \%$ & $100.0 \%$ \\
\hline \multirow{2}{*}{$\begin{array}{c}\text { Total } \\
\%\end{array}$} & 88 & 83 & 44 & 16 & 231 \\
\hline & $38.1 \%$ & $35.9 \%$ & $19.0 \%$ & $6.9 \%$ & $100.0 \%$ \\
\hline
\end{tabular}

Table 6 Pearson's correlation between distance and the utilization of ANC

\begin{tabular}{lcc}
\hline Test statistics & Utilization of ANC & Approximate distance \\
\hline Pearson Correlation & 1.00 & -0.039 \\
Sig. (2-tailed) & & 0.554 \\
$\mathrm{~N}$ & 231 & 231 \\
\hline
\end{tabular}

